\title{
Subacute Sclerosing Panencephalitis (SSPE) in HIV Infected Child
}

\author{
Manju Kumari ${ }^{1} \cdot$ Ira Shah $^{1} \cdot$ Naman S. Shetty $^{1}$ (i) $\cdot$ Shilpa Kulkarni ${ }^{2}$
}

Received: 13 September 2019 / Accepted: 24 December 2019/Published online: 14 January 2020

(C) Dr. K C Chaudhuri Foundation 2020

To the Editor: A 6-y-old HIV (Human immunodeficiency virus) infected orphan presented in October 2015 for management of his HIV infection. He also had a history of epilepsy and was on sodium valproate for the same. His last seizure was in October 2013. On presentation to us, examination was normal. His immunization status was not known but had received MMR and Hepatitis B vaccine at the orphanage. He was started on antiretroviral therapy (ART) consisting of zidovudine, lamivudine and efavirenz. Electroencephalogram (EEG) was normal and thus valproate was tapered and stopped by March 2016. In May 2016, he started having recurrent falls with drop attacks. Magnetic resonance imaging (MRI) brain was normal. EEG revealed bilateral frontal slow waves and frontal dominant burst of delta waves. He was restarted on sodium valproate. Levetiracetam and clonazepam were added since the drop attacks continued but there was no relief. In November 2016, cerebrospinal fluid (CSF) measles IgG 625 was positive, CSF HIV PCR was negative and CSF IgG was $12.90 \mathrm{mg} / \mathrm{dl}$ (Normal 0.48-5.86). Repeat EEG in March 2017 showed periodic to pseudo-periodic generalised bursts of slow delta activity with slow background activity confirming the diagnosis of subacute sclerosing panencephalitis (SSPE). Isoprinosine and ribavirin were added but he subsequently became bedridden.

Subacute sclerosing panencephalitis is caused by mutant measles virus and initially presents as mild intellectual deterioration and behavioral changes but as the disease progresses, clinical features range initially from motor disturbances, myoclonic jerks, visual disturbances to spasticity, quadriparesis,

Naman S. Shetty

naman.shetty@hotmail.com

1 Pediatric HIV Clinic, Department of Pediatrics, B J Wadia Hospital for Children, Mumbai, India

2 Pediatric Neurology Clinic, Department of Pediatrics, B J Wadia Hospital for Children, Mumbai, India loss of myoclonic jerks and coma [1]. Early-onset SSPE with a fulminant course has been described in children infected with HIV, as well as those perinatally infected with measles virus [2, 3]. In SSPE, CSF IgG concentration ranges from 10 to $54 \mu \mathrm{g} / \mathrm{dl}$, CSF measles IgG are raised and EEG shows a "burst suppression" pattern [4]. Similar changes were seen in our patient. Drugs like isoprinosine, interferon alfa, ribavirin, amantadine, cimetidine, corticosteroids, intravenous immunoglobulin are used with variable results in SSPE [1]. Measles vaccination is recommended as early as 6 mo of life in HIV infected infants as they are more likely to acquire measles before 9 mo of age and may not yet be severely immunocompromised at $6 \mathrm{mo}$ [5].

\section{Compliance with Ethical Standards}

Conflict of Interest None.

\section{References}

1. Garg RK. Subacute sclerosing panencephalitis. Postgrad Med J. 2002;78:63-70.

2. Koppel BS, Poon TP, Khandji A, Pavlakis SG, Pedley TA. Subacute sclerosing panencephalitis and acquired immunodeficiency syndrome: role of electroencephalography and magnetic resonance imaging. J Neuroimaging. 1996;6:122-5.

3. Dasopoulou M, Covanis A. Subacute sclerosing panencephalitis after intrauterine infection. Acta Paediatr. 2004;93:1251-3.

4. Dyken PR. Subacute sclerosing panencephalitis. Neurol Clin. 1985;3:179-95.

5. Embree JE, Datta P, Stackiw W, et al. Increased risk of early measles in infants of human immunodeficiency virus type 1-seropositive mothers. J Infect Dis. 1992;165:262-7.

Publisher's Note Springer Nature remains neutral with regard to jurisdictional claims in published maps and institutional affiliations. 